\title{
Gastón Carrasco
}

\section{Francine Masiello. El cuerpo de la voz: poesía, ética y cultura}

Rosario: Beatriz Viterbo; UNR, Editorial de la Universidad Nacional de Rosario, 2013. 320 págs.

Gastón Carrasco es Doctor (c) en Literatura por la Pontificia

Universidad Católica de Chile, Santiago de Chile. Licenciado

en Educación y Profesor de Lenguaje y Comunicación por

la Universidad Alberto Hurtado, Santiago de Chile. Becario

de la Fundación Pablo Neruda (2012). Entre sus últimas

publicaciones se encuentran "Crimen, responsabilidad

y violencia en la poesía chilena postdictatorial: revisión

a Whitechapel de Camilo Brodsky y Criminal de Jaime

Pinos" (Pangea, Universidad Diego Portales, 2012); "Función

Echevarría: crítica y circulación en torno a Roberto Bolaño" (en

prensa, Universidad de Valparaíso, 2014). Correo electrónico:

ggcarrasco@uc.cl

Documento accesible en línea desde la siguiente dirección: http://revistas.javeriana.edu.co

doi:10.11144/Javeriana.CL18-36.fmcv

\section{Cómo citar esta crítica:}

Carrasco, Gastón. Crítica de El cuerpo de la voz: poesía, ética y cultura,

de Francine Masiello. Cuadernos de Literatura 18.36 (2014): 399-

405. http://dx.doi.org/10.11144/Javeriana.CL18-36.fmcv 
CONOCIDA EN NUESTRO territorio, principalmente, por sus libros Entre civilización y barbarie: mujer, nación y cultura literaria en la Argentina moderna (1992, en castellano en Beatriz Viterbo, 1997) y El arte de la transición: cultura y neoliberalismo (Norma, 2001), Francine Masiello es considerada un referente necesario para aproximarse al estudio de la producción poética reciente, y no tanto, del Cono Sur del continente. La profesora de literatura hispanoamericana y literaturas comparadas en la Universidad de California en Berkeley nos invita a hacer lecturas culturales, más allá de lo textual, sin dejar nunca de lado la materialidad de la palabra. De una manera más sistematizada tal vez, Masiello nos presenta en su último libro, El cuerpo de la voz, una concepción y forma de leer literatura que involucra la palabra, la ética y la cultura. En este sentido, la presente reseña espera revisar y analizar críticamente la propuesta de Masiello, de manera que se pueda difundir su lectura y destacar su labor como referente para futuras investigaciones, debates culturales, literarios y sociales.

Ya en Lenguaje e ideologías: las escuelas argentinas de vanguardia (Hachette, 1986) Francine Masiello lee culturalmente la producción literaria, en este caso, de los primeros años del siglo XX. La revisión retrospectiva de la vanguardia como fenómeno estético/político le permite articular desde su presente la relación entre la experimentación con las sensaciones y la palabra y los procesos históricos que funcionaron como soporte o gatillos de estos. No es raro pensar que la tendencia en los ochenta fuera justamente revisitar los cimientos de lo que se denominaría postmodernidad, y dar cuenta, además, de las ideologías o condiciones que dieron pie al capitalismo tardío. Seis años después, Masiello se gana un lugar en la crítica al plantear una lectura de la literatura argentina moderna desde la figura de la mujer y la nación en Entre civilización y barbarie: mujer, nación y cultura literaria en la Argentina moderna.

Utilizando la clave de lectura fundamental de la dicotomía sarmientina, Masiello estudia la problemática de género en relación con el rol de la mujer en la cultura literaria argentina. A pesar de la determinación política y la interrelación entre vida pública y privada, plantea Masiello, los discursos sobre el género, la familia e incluso el amor se rearticulan constantemente. Esto es más patente en determinados momentos o periodos históricos, particularmente de crisis de la nación, en transiciones del Estado, pues el sistema de representaciones de género se modifica y las relaciones entre hombres y mujeres se alteran. La tesis, simple, pero efectiva, sirve para leer no solo la situación en Argentina, sino en otras geografías culturales. En cierto sentido, es lo que hace Masiello más tarde en El arte de la transición: cultura y neoliberalismo.

Siendo tal vez su libro más aclamado y consultado por los estudiosos, El arte de la transición: cultura y neoliberalismo, galardonado por la Modern Language 
Association como mejor libro del año dedicado a la cultura hispánica, revisa la producción de arte y literatura de Argentina y Chile en los años posteriores a sus respectivas dictaduras. Se mantienen las perspectivas de género y política presentadas en sus trabajos previos, pero se establece un modus operandi o sistema más reconocible y funcional de lectura. La representación, la experiencia y el lenguaje toman protagonismo y se vuelven el antecedente inmediato de su última entrega. Es particular en este libro el interés por las estrategias de resistencia y politización del arte en contra de la postmodernidad. Los comentarios sobre obras visuales o pictóricas permiten trazar diálogos interdisciplinarios que enriquecen el análisis de lo estrictamente literario. Además de mapear la producción artística, Masiello se arriesga a definir muchas veces qué significa hacer arte en transición, qué implica producir tras una dictadura, lo que ciertamente la posiciona en una discusión con varios capítulos por escribirse.

En El cuerpo de la voz: poesía, ética y cultura la apuesta es total. Masiello define y redefine sus concepciones sobre el quehacer poético desde una propuesta de experiencia física, corpórea: "el poema nos alcanza como una apelación al cuerpo, a los cinco sentidos" (9). En cierto sentido, la literatura atraviesa nuestros cuerpos, entra en contacto con nosotros. La voz poética nos enseña a escuchar, "se convierte en un recurso ético para asistirnos en la tarea de pensar nuestra relación con un tiempo y un lugar" (15). Masiello, desde el principio, se encarga de poner el acento en el componente ético de la poesía y la manera en que lo sensorial deviene en lo político: "el comienzo de un compromiso con el mundo tiene sus raíces en la forma material" (17). En los textos que siguen a la introducción se detiene en diversas temáticas y poetas para dar cuenta de su visión de la poesía. Revisaremos panorámicamente cada uno, para invitar a su lectura.

Los ritmos de lo social se encuentran imbricados en el texto literario, nos dice Masiello. En cierto sentido, la literatura reescribe un mundo social, de manera que el lector reconoce en ella algo de él y de su mundo. Y esto va más allá de la mimesis o representación de la realidad; tiene que ver con la aprehensión material que nuestros cuerpos hacen del poema. En "Las poéticas de la voz", primer capítulo del texto, a propósito de la obra de Leónidas Lamborghini, la profesora de la Universidad de California centra su análisis en el ritmo, la cadencia, la enunciación, a modo de reposición del "momento aurático de la oralidad" (22). Pues afirma que el mundo sensorial, comenzando por la audición, es el paso necesario para entenderse con el otro.

La reflexión respecto a Lamborghini implica escuchar como un modo de articulación de lo personal respecto a la experiencia general (26). Es mediante la escucha como nos construimos en cuanto sujetos e inventamos al hablante. 
Es entonces la voz la que construye un yo y un nosotros en el poema. Lo propio y lo ajeno se juegan sus espacios, sobre todo en el contexto de la globalización, donde se intenta anular la diferencia y establecer una homogeneización de todos los sujetos. La resistencia a esto implica construir una voz que contacte al otro y establezca una alianza ética. En cierto sentido, la poesía de Lamborhini vendría a desintegrar el lenguaje y poner en escena los orígenes de la voz (35). Al trabajar con los residuos del canon, el poeta argentino opera con la materialidad del lenguaje para reconfigurar históricamente la relación entre sonido y voz (37), más allá de parodias o de ser un eco de esas voces previas.

En "Poesía, voz y ritmo" Masiello se detiene a analizar la materialidad del lenguaje: ritmos, movimientos, voces. Bajo el concepto de comprensión a partir del cuerpo, problematiza nuestra relación con el mundo, la manera en que establecemos un pacto con el otro. Es quizá en este capítulo donde se dan más definiciones o ideas respecto a la poesía y al poema mismo. Poema, caja de resonancia llena de cuerpos y sonidos, intruso en los hábitos de lectura. Para dar cuenta de esto, se presentan las obras de Mirta Rosenberg y Arturo Carrera. En el caso de Rosenberg, se analiza El arte de perder (1998) en relación con la respiración, la lengua, el duelo y los sentidos. Por otro lado, en Carrera interesa la materialidad del poema en cuanto vínculo entre sensación y recuerdo, proximidad y alejamiento. Ambos autores le permiten a Masiello establecer relaciones en torno a la palabra y el recuerdo. La poesía, en estos casos, es reparadora, expone la herida y trata de curarla (71).

La reflexión del tercer capítulo, "Obrar y reunir", es tal vez una de las más interesantes del libro. Masiello nos lleva a pensar en la diferencia entre "obras completas" y "obra reunida" en nuestros días, lo que implica revisar los trayectos, evoluciones o cambios de un autor respecto a su obra. Detrás de todo, la palabra estilo surge como un coro invisible para interpelar nuestra relación con el autor; es quizá este el punto de interés de la autora. "El estilo es un conjunto de detalles insignificantes, un orden de sintaxis, un particular ensamblaje de elementos que se materializan y producen un efecto. Al mismo tiempo, podemos decir que el estilo produce voz, la voz de la escritura, la voz del escritor" (82). En este punto Masiello revisa la obra reunida de Diana Bellesi Tener lo que se tiene (Adriana Hidalgo, 2009) y la obra completa de Amelia Biagioni Poesía completa (Adriana Hidalgo, 2009).

En el capítulo "La naturaleza del poema" se piensa la representación del paisaje en la poesía latinoamericana, con sus antecedentes en el siglo XIX y su producción en el XX. Es de interés el paisaje para Masiello en cuanto vínculo con la experiencia personal y formación del yo poético. La serie de breves secciones 
dentro del capítulo, más allá de dar cuenta del trabajo investigativo de la autora, nos permite ir trazando un mapa de los movimientos del poeta sobre su geografía. El tránsito que hace Masiello va de Gabriela Mistral, Juan L. Ortiz y Joaquín Gianuzzi a Soledad Fariña, Diana Bellesi y Hugo Paledetti. Todos exponentes de diversas formas de aproximación a una representación de la naturaleza, y de la relación que el poeta establece con ella.

Uno de los núcleos teóricos del texto es el capítulo "Poesía y ética", texto donde Masiello despliega su análisis en torno al poroso tema de la relación entre poesía y política, desmarcándose de las lecturas tradicionales, ideológicas, que adscriben a poetas en ciertas corrientes de pensamiento político, limitando su trabajo con la palabra. La autora cita a Adorno al respecto: "la lectura que busca el referente político en el arte es tan perjudicial para la política como para el arte" (126). La postura claramente queda sujeta a debate, y estamos de acuerdo con dejar a los lectores sumarse o no Masiello. La idea de "fricción" es la que le da espesor al capítulo, y la revisión de diversas propuestas poéticas, con la historia política reciente del Cono Sur a cuestas.

En "Tiempo y respiración (nota sobre las poetas argentinas actuales)" Masiello intenta despejar el panorama de la poesía argentina femenina de cualquier rótulo o etiqueta que homogeneice u oculte su infinita complejidad. Junto a esto, el capítulo da cuenta de dos fenómenos que circulan en torno a la poesía producida por mujeres. Por un lado, la transformación de la tradición popular y la cultura de masas. Por otro, la insistencia en subrayar la intimidad de la voz (143). Interesante se vuelve el análisis del panorama crítico de recepción de la poesía y la articulación por parte de las poetas de una suerte de colectivo (conscientemente o no) alternativo a la producción masculina en los 80 y 90 en Argentina. Masiello se detiene en las constantes de su interés presentes en la poesía de estas poetas: materia del sonido, susurros del lenguaje, efectos en el cuerpo, interpelación al lector mediante el cuerpo de la voz.

A propósito de Luisa Futoransky, Masiello escribe el capítulo "Fugacidad y sombra", cuyo análisis se centra en la interpelación de la voz del poema al lector. Ante la incapacidad de traducir en palabras la experiencia de lectura, la sensación que nos produce corporalmente el poema, nos situamos en un lugar incómodo complejo de definir. He ahí una posible explicación, según Masiello, de la negación a aprender o enseñar poesía: “CCómo podemos enseñar lo que no tiene sentido dentro de las normas de la lógica?" (174). La poética nómade de Futoransky le permite a Masiello llegar a esta reflexión y pensar en el "decir sin decir" de la poesía, en el momento de asombro que genera el flujo de sonidos. 
El conocimiento sobre las estrategias de vanguardia le sirve a Masiello para escribir "Género, secreto y traducción (Joyce en Buenos Aires)" y hablarnos sobre el secreto. Entiéndase este como estrategia de "escribir en difícil", establecer un enigma entre autor y lector, pactar una tregua entre inteligibilidad y silencio. Todo esto exige la participación activa del traductor, quien, capaz de leer entre líneas, nos revela esa experiencia velada. Lo que no se puede nombrar, el tabú, es parte primordial de la propuesta de Joyce en el Ulises, su secreto. Este es el puntapié inicial para que Masiello exponga sus planteamientos en torno a la sexualidad, que muchas veces se plantea como enigma seductor que invita a, y niega, su traducción a experiencias sensibles reconocibles. La traducción, el punto de encuentro, es el núcleo de la cultura y literatura argentina, según Sarlo, y en extensión, de la cultura y literatura latinoamericana.

En un relato de tinte biográfico Masiello se aproxima al mundo social. En relación con la apropiación de lo "popular" por parte del cine, la música y la literatura, escribe el capítulo "Para leer lo popular: sonido, voz, contacto". El interés de los agentes de la cultura argentina por lo que ocurre en la densidad de lo social implica una dimensión política del concepto "popular", concepto que se resignifica y tiene consecuencias para la democracia del país trasandino. Interesante es aquí la inserción del comentario de Piglia respecto a lo popular: "es un efecto de la lectura" (cit. en Masiello 217). Se compara entonces un antes y un después, un margen y un centro, se lee o traza nuestra distancia respecto al otro. Luego de esto, Masiello entra en la discusión sobre las "pasiones" y su dimensión política, sobre la voz, el pueblo, la palabra y su materia.

En "El norte y el sur de la poesía" Masielllo retoma la idea de la irrupción del otro en la escena cultural metropolitana, la idea del sur como zona imaginada, espacio de políticas culturales nuevas, un paisaje otro, nueva nación, "espacio babélico que resiste la traducción" (237). Lo interesante de la teoría es lo flexible del concepto sur, o más bien, la asociación a un territorio específico que solemos hacer. Masiello se pregunta por el sur respecto a qué. Qué es el sur para Buenos Aires, qué es el sur para California. El imaginario subyacente permite figurar diversos "otros" más allá de la frontera. El sur es la heterogeneidad, la voz que escuchamos y reconocemos como ajena.

Haciendo una reflexión en torno al presente, al instante, inmediatez de la experiencia, Masiello presenta en "Cuerpo y catástrofe" un interés por el cuerpo y dolor del otro, y sus repercusiones en el cuerpo propio. Las sensaciones que nos genera la lectura implican un traslado desde la experiencia ajena a la propia. Ciertas experiencias empujan al sujeto a registrar su experiencia, para que luego sea aprehendida por otro en la lectura. Esto invita a entrar en la lectura del shock 
en la cultura y literatura latinoamericana reciente, cargada de cuerpos sufrientes, relatos abundantes y terribles de violencia sobre el cuerpo. La crisis implica un quiebre y desorden de los afectos. La escritura se resiente, pero está presente y persiste. En este capítulo el análisis se centra en relatos de Roberto Bolaño y Diamela Eltit que le permiten a Masiello establecer una reflexión en torno a conceptos como poder y biopolítica en el cuerpo social latinoamericano.

En el último capítulo del conjunto, "En los bordes del cráter (sobre la generación del go en Argentina)", como el estudio de Sarlo sobre Borges, Masiello se encuentra entre dos orillas y hace sus postulados en torno a las paradojas de la poesía resiente del país trasandino. Las dictaduras y los periodos de transición del Cono Sur como antecedentes históricos inmediatos sirven de marco para una literatura que se debate entre lo local y lo global, el centro y el margen, lo popular y lo docto, entre muchas otras dicotomías, o dialécticas más bien. Sean quizá los comentarios sobre Roberta Innamico, Verónica Viola Fisher y Fabián Casas los más interesantes, muy en la línea de La tendencia materialista. Antología crítica de la poesía de los 90 (Paradiso, 2012) de los compiladores Violeta Kesselman, Ana Mazzoni y Damián Selci; pues para Masiello la densidad material del poema es el piso necesario para percibir la poesía. Aunque más allá de lo material, su interés va justamente a la percepción sensorial, como se manifiesta en gran parte de los capítulos aquí reunidos. En este sentido, es el cuerpo el que define el poema, el que escucha y siente lo que la voz otra quiere comunicar en el yo lector. 